\title{
Research on the effect of industrial policy on the development of China's new energy vehicle power battery recycling industry chain
}

\author{
Qiao Shuang ${ }^{1, *}$, Liu Yingqi ${ }^{1}$, Zhang Lei $^{1}$ \\ ${ }^{1}$ Department of Business Administration, Beijing Jiaotong University, Haidian, Beijing, China
}

\begin{abstract}
With the increasing attention to ecological environmental protection and the rapid consumption of global energy resources, the new energy vehicle industry is attracting more and more attention from all over the world, and the vehicle power battery has ushered in the stage of mass scrapping. China's power battery recycling industry is in the primary stage of development. In order to analyze the impact of relevant industrial policies on the development of the industry chain, this paper describes the development status of the power battery recycling industry by drawing the panorama of the industry chain of power battery recycling. At last, the industrial policy of power battery recycling was evaluated qualitatively and quantitatively by analytic hierarchy process, and on this basis, some policy suggestions to promote the development of industrial chain were put forward.
\end{abstract}

\section{1 introduction}

In recent years, with the increasing attention of countries around the world to ecological and environmental protection and the rapid consumption of global energy resources, the new energy vehicle industry has also attracted more and more attention from countries around the world. In order to promote the upgrading of industrial structure and achieve the goal of energy conservation and emission reduction, China also insists on vigorously developing the new energy vehicle industry. According to the data of the China Association of Automobile Manufacturers, in 2020, the output of new energy vehicles in China was 1.366 million and the sales volume was 1.367 million, up $7.5 \%$ and $10.9 \%$ year on year, among which the output of pure electric vehicles was 1.105 million and the sales volume was 1.116 million.

Power battery is the core of pure electric vehicle and the key to the development of new energy vehicle industry. According to the data released by China Automotive Power Battery Industry Innovation Alliance, the cumulative output of power batteries in China in 2020 is $83.4 \mathrm{GWh}$, the cumulative sales are $65.9 \mathrm{GWh}$, and the loading volume is $63.6 \mathrm{GWh}$, a year-on-year increase of $2.3 \%$. Thus, in recent years, with the rapid increase in the production and sales of new energy vehicles, vehicle power batteries have also ushered in the stage of mass scrapping, which is bound to have a huge impact on the ecological environment and resource reuse. The development of power battery recycling industry determines, to a large extent, whether China's new energy vehicle industry can develop sustainably and maintain its leading international advantage. Therefore, the development of power battery recycling industry has attracted more and more attention from the country, major enterprises and relevant scholars.

In recent years, domestic scholars have conducted a large number of studies on the power battery recycling industry, mainly focusing on the impact of power battery recycling policies and regulations, countermeasures and suggestions, industry and business model, recycling model and recycling network system and other fields. Some scholars have studied the policies and experiences of power battery recycling in developed countries such as Europe and America [1]. In this paper, the relevant regulations and policies of power battery in China are studied ${ }^{[2-3]}$. In this paper, the existing problems of power battery recycling system in China are analyzed ${ }^{[4-5]}$. At the same time, some countermeasures and suggestions are put forward to strengthen the power battery recycling ${ }^{[6-7]}$; in the field of power battery recycling industry and business model, the status quo of power battery recycling industry was analyzed ${ }^{[8]}$. In this paper, the industrialization development of waste power battery recycling is analyzed ${ }^{[9]}$, and the business model of power battery recycling industry was studied ${ }^{[10-11]}$; in addition, some scholars also on the current situation of power battery recycling ${ }^{[12]}$, recycling mode and recycling network system were studied.

Through reading relevant literature, it is found that the previous research lacks the research on the impact of industrial policy on the development of China's new energy vehicle power battery recycling industry chain. This paper will describe the development status of the power battery recycling industry by drawing the panorama of the industry chain of power battery recycling. Secondly,

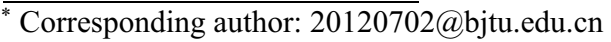


on the basis of formulating the power battery recycling industrial policy evaluation system, this paper will use the analytic hierarchy process to determine the weight of each index, conduct quantitative and qualitative analysis of the policy factors, in order to analyze the impact of power battery recycling industrial policy on the development of the industrial chain and put forward some constructive suggestions.

\section{Current situation of automotive power battery recycling industry chain}

\subsection{Panorama of automotive power battery recycling industry chain}

The Chinese government highly encourages the development of power battery recycling industry. With the rapid growth of waste power battery production, the industrial chain has been further improved, and more and more related enterprises have flooded into the upper, middle and lower reaches of the industrial chain, mainly some battery enterprises and automobile enterprises, as shown in Figure 1.

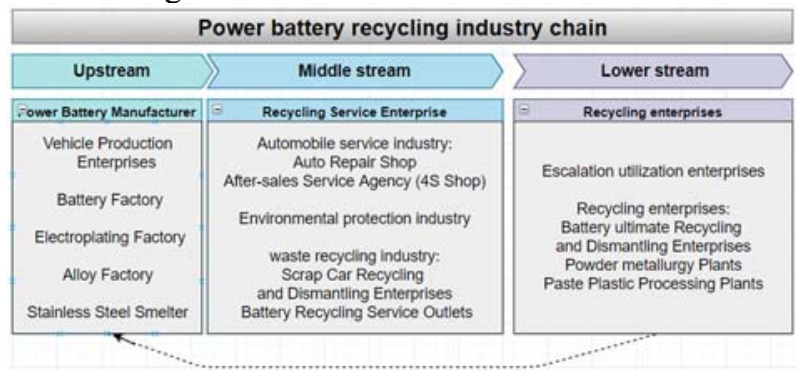

Fig.1 Panoramic view of power battery recycling industry chain

Upstream of the industry chain are power battery manufacturers, mainly including some battery-related manufacturers, such as battery factories, electroplating factories, cemented carbide factories, stainless steel smelters, in addition to new energy vehicle production enterprises. Battery production enterprises in the process of production of unqualified batteries and new energy vehicle production enterprises in the assembly of power battery for testing out does not conform to the requirements of the battery will be used as a special kind of "product" middle reaches into the industry chain, become the industry chain in the middle one of a series of recycling industries raw materials.

The middle of the industrial chain is a power battery recycling service enterprise, which mainly consists of three parts: the first part is the automobile service industry, such as automobile repair shop, after-sales service center (4S) shop, which mainly collects the used power batteries replaced during the maintenance of new energy vehicles, especially pure electric vehicles. The second part is some environmental protection industries, which are also committed to collecting used power batteries. The third part is the waste recycling industry, such as some battery recycling service outlets and scrap car recycling and dismantling enterprises, which dismantle the used power batteries from scrapped cars and recycle them. Through the analysis, we can see that all kinds of enterprises in the middle of the power battery recycling industry chain are in close contact with consumers. They mainly collect the waste batteries produced by the upstream enterprises and consumers and deliver them to the downstream enterprises of the industry chain.

Downstream of the industrial chain are enterprises involved in cascade utilization and recycling. The former is to reprocess waste power batteries to achieve reuse. The latter mainly include battery recycling and dismantling enterprises, powder metallurgy plants, waste plastic processing plants. They mainly dismantle the waste power batteries and separate out a variety of renewable resources, such as recycled metals, steel raw materials, fuel, which can be used as raw materials for battery manufacturers upstream of the industrial chain. Therefore, different from the industrial chain structure of other traditional industries, a dotted line is connected between the downstream and upstream of the industrial chain in this paper, indicating that the industrial chain of power battery recycling is not a completely single flow structure.

\subsection{Development Status of Vehicle Power Battery Recycling Industry under the Influence of Policies}

In recent years, with the rapid increase in the production and sales of new energy vehicles, vehicle power batteries have also ushered in the stage of mass scrapping. According to relevant data, China's waste power battery volume in 2019 is about 63,900 tons. After comprehensively considering the annual production of new energy vehicles, battery life and other factors, China Battery Alliance predicts that by 2025, the amount of used power batteries in China will reach 116GWh (about $780,000 \mathrm{t}$ ), and the market scale of power battery recycling is expected to exceed 37 billion yuan. The power battery recycling market is full of business opportunities and profits, and companies with technology and cost advantages will come out on top.

However, at the national level, although a number of policy documents related to the power battery recycling industry have been issued since 2012, the current progress is not smooth. In 2020, the amount of power battery retired Beijing alone has more than 2.1 GWh (23000 tons), accounted for $10 \%$ of the country's total, and each year the amount of power battery retired growth is expected to more than $30 \%$, and in the face of such a large retired power battery capacity, Beijing is still under construction waste power battery special comprehensive processing center.

In addition, as the new energy automotive industry and the vigorous development of the power battery industry, involving the global power battery recycling industry chain enterprises, this paper focuses on the number of several types of the enterprise greatly influenced by policy, mainly including retrieving and dismantling scrapped automobiles enterprises and old power battery arrangement in use and recycling recycling enterprises. These two types of enterprises need to strictly abide by the relevant industry norms issued by the state. 
According to the National List of Recycling and Disassembling Enterprises for Scrapped Motor Vehicles published by the Department of Market System Construction of the Ministry of Commerce in June 2019, there are a total of 732 recycling and disassembling enterprises for scrapped motor vehicles that meet the requirements. In 2018, the Department of Energy Conservation and Comprehensive Utilization of the Ministry of Industry and Information Technology announced that there were 5 enterprises in line with the first batch of "New Energy Vehicle Waste Power Battery Comprehensive Utilization Industry Specifications and Conditions". In December 2020, there were 22 enterprises in line with the second batch of regulations, a total of 32 . In the second batch of the list, only one enterprise, Quzhou Huayu Resources Recycling Technology Co., Ltd., applied for ladder utilization and recycling at the same time. There were 13 enterprises applying for ladder utilization and 8 enterprises applying for recycling. Only a few enterprises comply with the national regulations of the power battery recycling industry norms, thus it can be seen that the national policy guidance, relevant technology restrictions and enterprise cost control and other aspects of the problem seriously affects the development of the current power battery recycling industry.

\section{Empirical analysis on the impact effect of China's automotive power battery recycling industry policy}

\subsection{Establishment of policy evaluation index system}

This paper divides the evaluation index system of China's automotive power battery recycling industry policy into three parts: industrial promotion index, technical standard index and publicity index. Details are shown in Table 1.

Tab.1 Policy evaluation index system of power battery recycling industry

\begin{tabular}{cc}
\hline Level & The secondary indicators \\
indicators & Industry access standard(C1) \\
& Related technology conversion rate and \\
marketization degree(C2) \\
Industry & Industrial Development Plan(C3) \\
Driving & Corporate subsidies(C4) \\
Indicators & Research grants(C5) \\
(B1) & Recycling service network \\
& construction(C6) \\
& Battery production technology(C7) \\
Technical & Battery disassembly technology(C8) \\
standard & Battery recycling technology(C9) \\
Index & Pollution control technology of waste \\
(B2) & battery(C10) \\
Propaganda & Pilot recycling(C11) \\
Indicators & Raise public awareness of recycling(C12) \\
(B3) & Recycling subsidies(C13) \\
\hline
\end{tabular}

1) Indexes of industrial promotion. Comprehensive and reasonable, the feasibility of high power battery recycling industries to promote policy to a great extent, determines the future development of the industry status, subdivision down mainly includes power battery recycling industry access standards, relevant technical conversion rate and the degree of marketization, the industrial development planning, corporate subsidies, research grants, recycling service network construction.

2) Technical standard indicators. Emerging industries must be supported by corresponding technologies if they want to achieve long-term development. The technical standard indexes of power battery recycling industry mainly include battery production technology, battery disassembly technology, battery recycling technology, waste battery pollution prevention technology.

3) Publicity indicators. Although the public has established a certain awareness of environmental protection, but the understanding of power battery recycling is not enough, the need for policy publicity to promote the recycling of waste power battery, mainly including recycling pilot, improving public awareness of recycling, recycling subsidies.

\subsection{Analytic Hierarchy Process for Automotive Power Battery Industrial Policy}

Analytic Hierarchy Process (AHP) is a decision analysis method of hierarchy weight. Based on the evaluation system of power battery recycling industrial policy established above, this paper will determine the weight of each index by AHP, conduct quantitative and qualitative analysis on the influencing factors of the policy, and evaluate the power battery recycling industrial policy.

\subsubsection{Construct the judgment matrix of pairwise comparison between indicators}

The importance degree of each index is obtained through investigation, and the judgment matrix of each level is determined by using the nine-point scale method. Taking B-layer indicators as an example, B1 index is more important than B3 index, B2 index is obviously more important than B3 index, and B1 index is slightly more important than B2 index. Thus, the judgment matrix A of B-layer indicators can be obtained as follows:

$$
A=\left[\begin{array}{ccc}
1 & 3 & 7 \\
1 / 3 & 1 & 5 \\
1 / 7 & 1 / 5 & 1
\end{array}\right]
$$

\subsubsection{Determination of index weights and consistency test}

$$
C R=\frac{C I}{R I}
$$

In general, the smaller the CR value of the matrix, the better the consistency of the judgment matrix. When $\mathrm{Cr}$ $\leq 0.1$, the consistency of judgment matrix can be accepted. Otherwise, the assignment of the judgment matrix should be modified until $\mathrm{CR} \leq 0.1$.

Take the B-layer index as an example to determine the index weight and carry out consistency test.

1) Determine the index weight 
a) Normalize the judgment matrix A by columns:

$$
\begin{gathered}
\widetilde{w}_{i j}=\frac{a_{i j}}{\sum_{i=1}^{n} a_{i j}} \\
A=\left[\begin{array}{ccc}
1 & 3 & 7 \\
1 / 3 & 1 & 5 \\
1 / 7 & 1 / 5 & 1
\end{array}\right] \rightarrow\left[\begin{array}{lll}
0.678 & 0.714 & 0.538 \\
0.226 & 0.238 & 0.385 \\
0.097 & 0.048 & 0.077
\end{array}\right]
\end{gathered}
$$

b) Add the rows of the normalized matrix to get a column vector:

$$
\begin{gathered}
\vec{w}_{i j}=\sum_{j=1}^{n} \widetilde{w}_{i j} \quad i=1,2, \ldots, \mathrm{n} \\
{\left[\begin{array}{c}
1.93 \\
0.849 \\
0.222
\end{array}\right]}
\end{gathered}
$$

c) The weight vector is obtained after normalization of the obtained column vector:

$$
\begin{array}{r}
\widetilde{w}=\left(\widetilde{w}_{1}, \widetilde{w}_{2}, \cdots, \widetilde{w}_{n}\right)^{T} \\
{\left[\begin{array}{c}
1.93 \\
0.849 \\
0.222
\end{array}\right] \rightarrow\left[\begin{array}{l}
0.643 \\
0.283 \\
0.074
\end{array}\right]=\widetilde{w}}
\end{array}
$$

2) Consistency check

a) Calculate the eigenvalue of the judgment matrix and take the maximum eigenroot $\lambda_{\max }$

$$
\begin{gathered}
\operatorname{make}\left[\begin{array}{ccc}
1-\lambda & 3 & 7 \\
1 / 3 & 1-\lambda & 5 \\
1 / 7 & 1 / 5 & 1-\lambda
\end{array}\right]=0 \\
\lambda_{\max }=3.065
\end{gathered}
$$

b) Calculate consistency index $\mathrm{CI}$ :

$$
\begin{gathered}
C I=\frac{\lambda_{\max }-\mathrm{n}}{n-1} \\
C I=\frac{\lambda_{\max }-\mathrm{n}}{n-1}=\frac{3.065-3}{3-1}=0.0325
\end{gathered}
$$

c) Calculate the consistency ratio $\mathrm{CR}$ :

$$
C R=\frac{C I}{R I}=\frac{0.0325}{0.52}=0.0625<0.1
$$

$C R=0.0625 \leq 0.1$, in line with the requirements of consistency test. Details are shown in Table 2.

Tab.2 The weight coefficient and consistency test results of each index of grade B under index A

\begin{tabular}{cccccc}
\hline A & B1 & B2 & B3 & $\begin{array}{c}\text { Weight } \\
(\%)\end{array}$ & rank \\
\hline B1 & 1 & 3 & 7 & 64.3 & 1 \\
B2 & $1 / 3$ & 1 & 5 & 28.3 & 2 \\
B3 & $1 / 7$ & $1 / 5$ & 1 & 7.4 & 3 \\
$\lambda_{\text {max }}=3.065$ & $C I=0.0325$ & $R I=0.52$ & $C R=0.0625$ \\
\hline
\end{tabular}

In the same way, weight coefficients and consistency test results of all C-level indicators under B1, B2 and B3 can be calculated respectively, as shown in Table 3, Table 4 and Table5.

Tab.3 The weight coefficient and consistency test results of each index of grade $\mathrm{C}$ under index $\mathrm{B} 1$

\begin{tabular}{ccccccccc}
\hline B1 & C1 & C2 & C3 & C4 & C5 & C6 & Weight (\%) & rank \\
\hline C1 & 1 & 5 & 6 & 3 & 5 & 4 & 42 & 1 \\
C2 & $1 / 5$ & 1 & 3 & $1 / 4$ & 1 & $1 / 3$ & 7.65 & 4
\end{tabular}

$$
\begin{aligned}
& \begin{array}{lllllllll}
\text { C3 } & 1 / 6 & 1 / 3 & 1 & 1 / 5 & 1 / 3 & 1 / 4 & 4 & 6
\end{array} \\
& \begin{array}{lllllllll}
\mathrm{C} 4 & 1 / 3 & 4 & 5 & 1 & 4 & 2 & 23.1 & 2
\end{array} \\
& \begin{array}{lllllllll}
\text { C5 } & 1 / 5 & 1 & 3 & 1 / 4 & 1 & 1 / 3 & 7.65 & 4
\end{array} \\
& \begin{array}{lllllllll}
\mathrm{C} 6 & 1 / 4 & 3 & 4 & 1 / 2 & 3 & 1 & 15.6 & 3
\end{array} \\
& \lambda_{\max }=6.287 \quad C I=0.0574 \quad R I=1.26 \quad C R=0.046
\end{aligned}
$$

Tab.4 The weight coefficient and consistency test results of each index of grade $\mathrm{C}$ under index B2

\begin{tabular}{ccccccc}
\hline $\mathrm{B} 2$ & $\mathrm{C} 7$ & $\mathrm{C} 8$ & $\mathrm{C} 9$ & $\mathrm{C} 10$ & $\begin{array}{c}\text { Weight } \\
(\%)\end{array}$ & rank \\
\hline $\mathrm{C} 7$ & 1 & $1 / 5$ & $1 / 7$ & $1 / 3$ & 5.7 & 4 \\
$\mathrm{C} 8$ & 5 & 1 & $1 / 3$ & 3 & 26.3 & 2 \\
$\mathrm{C} 9$ & 7 & 3 & 1 & 5 & 55.8 & 1 \\
$\mathrm{C} 10$ & 3 & $1 / 3$ & $1 / 5$ & 1 & 12.2 & 3 \\
$\lambda_{\max }=4.117$ & $C I=0.039$ & $R I=0.89$ & $C R=0.0438$ \\
\hline
\end{tabular}

Tab.5 The weight coefficient and consistency test results of each index of grade $\mathrm{C}$ under index $\mathrm{B} 3$

\begin{tabular}{cccccc}
\hline B3 & C11 & C12 & C13 & $\begin{array}{c}\text { Weight } \\
(\%)\end{array}$ & rank \\
\hline $\mathrm{C} 11$ & 1 & 5 & 3 & 63.3 & 1 \\
$\mathrm{C} 12$ & $1 / 5$ & 1 & $1 / 3$ & 10.6 & 3 \\
$\mathrm{C} 13$ & $1 / 3$ & 3 & 1 & 26.1 & 2 \\
$\lambda_{\max }=3.0385$ & $C I=0.01925$ & $R I=0.52$ & $C R=0.037$ \\
\hline
\end{tabular}

\subsubsection{Result analysis}

According to the above data, it can be concluded that among all the indicators in the B layer under the index A, the $\mathrm{B} 1$ industry promotion index with the largest weight is $64.3 \%$. Next is B2 technical standard index, the weight is $28.3 \%$.

Among all the indicators of $\mathrm{C}$ layer under the $\mathrm{B} 1$ industry promotion index, $\mathrm{C} 1$ industry access standard has the largest weight, which is $42 \%$; Next came C4 enterprise subsidies and $\mathrm{C} 6$ recycling service network construction, with a weight of $23.1 \%$ and $15.6 \%$ respectively.

Among the indicators of $\mathrm{C}$ layer under B2 technical standard, C9 battery recycling technology has the largest weight, which is $55.8 \%$. It was followed by $\mathrm{C} 8$ battery disassembly technology with a weighting of $26.3 \%$.

Among all the indicators in the $\mathrm{C}$ layer under the $\mathrm{B} 3$ publicity index, the $\mathrm{C} 11$ recycling and utilization pilot project has the largest weight, accounting for $63.3 \%$.

\section{4 conclusion}

To sum up, the relevant policies and their evolution trend of China's power battery recycling industry are summarized in this paper, and the development status of the power battery recycling industry is described by drawing the panorama of the industry chain of power battery recycling and the network relationship diagram of its stakeholders. Finally, the power battery recycling industrial policy was evaluated qualitatively and quantitatively by the analytic hierarchy process (AHP), and the effect of the power battery recycling industrial policy on the development of the industrial chain was analyzed. On this basis, this paper puts forward several policy suggestions, hoping to provide some inspiration for promoting the future development of the industry:

1) Attach importance to industrial development, 
promote the participation of relevant enterprises, and form a complete industrial system. In the current policy environment, accord with standard of power battery recycling industry enterprises are in the minority, the country should attach great importance to the industry as a whole development, clear industry overall development plan, issued a variety of incentives, promote enterprise into the industrial chain, and strengthen the construction of recycling service outlets, more perfect power battery recycling system construction.

2) Increase research and development efforts to promote technological progress. Battery recycling technology breakthrough will greatly promote the development of industry, the country when it makes policy should consider to build a market environment of innovation, increase subsidies in technology research and development of the policy, standardize the industry technical standards, establish a perfect system of industry standards, promote from battery production to recycle the industrial chain of the overall development.

3) Establish a market mechanism, strengthen publicity, and improve the awareness of social recycling. On the basis of the existing policies, the existing enterprises in the industrial chain should be guided to speed up the construction of recycling channels, establish a marketoriented system, and achieve win-win cooperation among the stakeholders of the industrial chain. In addition, through the promulgation of various subsidies and preferential policies, promote enterprises and relevant consumers and actively participate in power battery recycling, improve the overall recycling awareness of the society, and promote the development of the industry.

\section{Acknowledgement}

This work is supported by Science and Technology Project of SGCC 2020 (Research on Business Model Design and Iteration Technology for Emerging Business of Energy Internet, No. 1400-202057429A-0-0-00).

\section{References}

1. Ding Hui, (2016) American Power Battery Recycling Management Experience and Enlightenment. J. Environmental Protection, 44(22): 69-72.

2. Wang Chen, Jiang Tingyu, Jiang Boxin, (2018) Research progress and prospect of waste power battery recycling. J. Renewable Resources and Circular Economy, 11(10):32-35.

3. Yang Yaokun, Zhang Bo, Liang Yunlin, (2021) Analysis of Recycling Policy and Technology Status of Waste Power Battery. J. Automobile \& Accessories, 1: $50-51$.

4. Wang Ban, (2019) Development Status and Suggestions of Power Battery Recycling System for New Energy Vehicles in China. J.Logistics Science and Technology, 42(02): 72-75.

5. Zhang Boni, Guan Yixin, Li Yuxuan, (2019) Problems Analysis and Development Suggestions Based on the Current Situation of New Energy Vehicle Power
Battery Recycling. J.Time Automotive, 17: 71-72.

6. Zhao Shijia, $\mathrm{Xu}$ Nan, Qiao Yingjun, (2018) Suggestions on Accelerating China's New Energy Vehicle Power Battery Recycling. J. Engineering Sciences, 20(01):144-148.

7. Chen Yisong, Zhao Junwei, Qiao Jie, (2018) Analysis and Suggestions on Power Battery Recycling for Electric Vehicles in China. J. Transactions of the Chinese Society of Automotive Engineering, 8(02): 97-103.

8. Chen Jiqing, Weng Chubin, Lan Fengchong, (2019) Current situation and trend of power battery industry under policy influence. J. Science and Technology Management Research,39(09):148-157.

9. Zhu Guocai, (2018) Progress in Industrialization of Waste Power Lithium-ion Battery Recyculation. J. New Materials Industry,3:31-33.

10. Xie Yinghao, Yu Haijun, Ou Yannan, (2017) Research on Business Model of Recycling Power Battery. J. Power Supply Technology,41(04):644-646.

11. Tao Zhijun, Jia Xiaofeng(2018)Research on China's power battery recycling industry business model. J. Automotive Industry Research,10:33-42.

12. Xiao Wukun, Zhang Hui (2020) Recycling Survey of Waste Lithium-ion Batteries for Vehicles in China. J. Power Supply Technology,44(08):1217-1222. 